\title{
Biophysical Reviews: from the umbra of 2020-2021 into the antumbra of 2022
}

\author{
Damien Hall ${ }^{1,2}$
}

Accepted: 10 February 2022 / Published online: 23 February 2022

(C) International Union for Pure and Applied Biophysics (IUPAB) and Springer-Verlag GmbH Germany, part of Springer Nature 2022, corrected publication 2022

\begin{abstract}
This sub-Editorial for Volume 14 Issue 1 (2022) first makes comment on the current issue and then describes matters of interest related to the journal's activities in 2022-chief among which are (i.) the announcement of the winner of the 2022 Michèle Auger Award for Young Scientists' Independent Research, (ii.) an outline of this year's finalized Special Issue (SI) lineup, (iii.) a description of a new production service offered by Springer to those submitting to the Biophysical Reviews journal, and (iv.) an introduction of newly appointed members of the Biophysical Reviews' Editorial Board.
\end{abstract}

While the current world situation is still somewhat bleak there are signs that as we move further on from the point of its initial outbreak, humanity's relationship with the SARS-CoV-2 virus is beginning to change from one of pandemic crisis, to the more familiar situation of endemic management, able to be countered through the application of best clinical practice and public health measures. Time will tell if this assessment is true and whether, or not, 2022 proves to be the year from which we collectively begin to emerge from the shadow cast by the COVID-19 outbreak. Nevertheless, irrespective of what may happen, the journal, like all other institutions, has a job to get on with, and the opening of 2022 represents an excellent opportunity for clearly restating what that job is.

\section{What is the job of Biophysical Reviews?}

Publishing its first article in 2009, the "Biophysical Reviews" journal was created by the International Union for Pure and Applied Biophysics (IUPAB) [Morales 2021;

Damien Hall

hall.damien@staff.kanazawa-u.ac.jp;

damienhall30@gmail.com

1 WPI Nano Life Science Institute, Kanazawa University, Kakumamachi, Kanazawa, Ishikawa 920-1164, Japan

2 Department of Applied Physics, Aalto University, 00076 Aalto, Finland
IUPAB 2022] to assist in furthering its philanthropic goals. Created in partnership with the Springer-Nature Corporation, the mandated aims of Biophysical Reviews are as follows.

(i) Publish timely and critical review articles on the topic of biophysics by recognized experts in the field

(ii) Assist with the development and publication of biophysics-related research across all areas of the world

(iii) Promote and advocate for the internationalization of biophysical research

(iv) Act as a secondary source of revenue for IUPAB (alternative to funds raised through IUPAB membership fees)

Like its fellow international unions for chemistry (IUPAC) and physics (IUPAP), IUPAB is a non-profit affiliate of the International Science Council (ISC) - the world's largest non-governmental body for science policy advocacy [ISC 2022]. In this Editorial, we describe the activities of Biophysical Reviews in 2022 , initially beginning with a short precis of the current issue.

\section{SI on the Australian Society for Biophysics}

The current issue focusing on the Australian Society for Biophysics (ASB) [dos Remedios et al. 2022] is the second Special Issue (SI) in the Biophysical Reviews national biophysical society partnership program series [Hall 2020a]. The aim of these national society themed SIs is to bring 
to the front a particular country's biophysical societydescribing the structure of the organization, their outreach activities, and the types of research they specialize in along with the opportunities (and mechanisms) available for collaboration. With the first national biophysical society feature SI being delivered by one of the world's largest and oldest societies, the Biophysical Society of Japan (BSJ) [Komatsuzaki et al. 2020; Harada 2020], the current SI feature on the ASB provides a window into the workings of a smaller society but one that consistently punches well above its weight [dos Remedios et al. 2022; Hill 2022]. While I refer the reader to the Issue Editorial for a more complete description of the issue contents, it is worth pointing out here the balance of Commentaries, Letters, and Reviews appearing in the current issue (Table 1). As can be seen, the ASB SI is divided into two major sections, a front section containing Editorials, Commentaries, and Letters, and the main scientific body section, containing short and long format review articles. Within the front section, following the lead Editorial [dos Remedios et al. 2022] are two particularly notable contributions, a Commentary from the society President, Dr. Adam Hill, describing the nature and constitution of the ASB [Hill 2022], and a short Letter, from Prof. Boris Martinac, ${ }^{1}$ describing some additional historical context to this years' Nobel Prize in Physiology and Medicine, awarded to Prof. Ardem Patapoutian for his discovery of Piezo 1 and 2 mechanosensitive ion channels [Martinac 2022]. In the main body of the SI (Table 1), the SI Editors have collectively assembled over twenty-five review articles grouped into the following five themes which reflect particular research strengths and interests within the ASB membership,

(i) Advanced bioimaging and spectroscopy

(ii) Next generation sequencing

(iii) Membrane proteins and receptors

(iv) Cancer structural biology

(v) Cardiovascular and muscle physiology

On behalf of the journal, I would like to thank the contributors and also congratulate the SI Guest Editors (Charles Cranfield, Donna Whelan, Charles Cox, Keith Shearwin, Joshua Ho, Toby Allen, Risa Shibuya, Emi Hibino, Kumiko Hayashi, Cristobal dos Remedios, and Amy Li) for their efforts in assembling this interesting line up of articles, and by doing so, providing insight into the workings of the Australian Society for Biophysics.

\footnotetext{
${ }^{1}$ A truly pioneering scientists within the mechanosensitive ion channel field.
}

\section{Michèle Auger Award Winner}

In late 2018, Prof. Michèle Auger, a long-time and wellrespected member of the Biophysical Reviews Editorial Board, sadly lost her fight against cancer. More can be read about the life and research of Prof. Auger in the following obituary published in the IUPAB newsletter [IUPAB 2019]. At the 2019 Editorial board meeting, the journal initiated an award to honor her service and perpetuate the memory of her association with Biophysical Reviews. The award was also designed to promote her interest in recognizing and inspiring younger scientists. Titled "The Michèle Auger Award for Young Scientists' Independent Research," this award is now in its third year of operation [Hall 2020b; 2021a]. Candidates for the award, who must be younger than 40 years of age at the time of the October $31^{\text {st }}$ nomination deadline, may either self-nominate or be nominated by an interested colleague. Details for submission are provided in each year's Issue 3 of Biophysical Reviews (released in June, e.g., see [Hall 2020c; 2021b]) with this call for submission marking the opening of the award for that year. Designed to be the least (personally) onerous and demanding of awards, nominated candidates are only required to provide a one-page curriculum vitae along with their five best papers. All candidates have their papers and c.v. read by a minimum of eight judges from a pool of 15 total. Judges are selected from senior members of the international biophysics community with all judges being at the head of laboratory/head of institute level. Judges are requested to make their assessment based on the following three criteria (a) independence, (b) originality, and (c) excellence. For each candidate, a simple average of all judge scores was taken with uncertainty in the scoring indicated as a standard error. The 2022 Award received 17 nominations in total with the ordinal ranking of the average score for each candidate displayed in Fig. 1. As can be seen this year's award was again very tight with some common degree of overlap among the error envelope seen for the top four candidates. Despite the closeness of the scores, in the absence of a numerical tie, there can only be one winner. And with the preceding description as prolog, it is with great pleasure that we announce the winner of the 2022 Michèle Auger Award for Young Scientists' Independent Research as Assoc. Prof. Miho Yanagisawa of the University of Tokyo. Specializing in intersectional research involving the application of soft matter physics concepts (polymer and phase behavior) to in vitro biophysical experiments pitched at the level of artificial cells, Miho's research theme is aimed at developing fundamental principles which govern cell organization and behavior. More about her research can be read at her laboratory websites. 
Table 1 Contributions to the Special Issue on the Australian Society for Biophysics (ASB) 2022

Articles divided by section

\section{Front matter material}

A Special Issue of the Australian Society for Biophysics

Biophysical Reviews: from the umbra of 2020-2021 into the antumbra of 2022

Biophysics in the time of COVID

2021 Nobel Prize for Mechanosensory Transduction

Biophysical Reviews Special Issue call: Computational biophysics and structural biology of proteins-A Special Issue in honor of Prof. Haruki Nakamura's $70^{\text {th }}$ birthday

\section{Applications of advanced imaging and spectroscopy}

Recent advances in the standardization of fluorescence microscopy for quantitative image analysis

Insights into HIV uncoating from single-particle imaging techniques

Opto-thermal technologies for microscopic analysis of cellular temperature-sensing systems

Characterizing conformational ensembles of multi-domain proteins using anisotropic paramagnetic NMR restraints

NMR spectroscopy of lipidic cubic phases

Next generation sequencing

Dissecting cricket genomes for the advancement of entomology and entomophagy

DNA sequencing: an overview of solid-state and biological nanopore-based methods

Membrane proteins and receptors

Model architectures for bacterial membranes

Lipid-mediated antimicrobial resistance: a phantom menace or a new hope?

The interaction of steroids with phospholipid bilayers and membrane

Aquaporin ion conductance properties defined by membrane environment, protein structure, and cell physiology

A biophysical perspective of the regulatory mechanisms of ezrin/radixin/moesin proteins

Computational studies of Piezo1 yield insights into key lipid-protein interactions, channel activation, and agonist binding

Characteristic structural difference between inactive and active states of orexin 2 receptor determined using molecular dynamics simulations

Structural biology of cell surface receptors implicated in Alzheimer's disease

How plants solubilize seed fats: revisiting oleosin structure and function to inform commercial applications

\section{Cancer therapeutic targets}

Potential of rescue and reactivation of tumor suppressor p53 for cancer therapy

Urokinase plasminogen activator as an anti-metastasis target: inhibitor design principles, recent amiloride derivatives, and issues with human/mouse species selectivity

Metamorphosis of prostate specific membrane antigen (PSMA) inhibitors

Gold-based hybrid nanostructures: more than just a pretty face for combinational cancer therapy

\section{Cardiovascular and muscle physiology}

Fibrosis and impaired $\mathrm{Ca} 2+$ signaling in heart failure

The function and regulation of calsequestrin-2: implications in calcium-mediated arrhythmias

Metabolic and electrolyte abnormalities as risk factors in drug-induced long QT syndrome

Peripartum cardiomyopathy: a global effort to find the cause and cure for the rare and little understood disease

A bibliometric review of peripartum cardiomyopathy compared to other cardiomyopathies using artificial intelligence and machine learning

Paradoxes of Hymenoptera flight muscles, extreme machines
Article type Reference

Editorial [dos Remedios et al. 2022]

Editorial [Hall 2022]

Commentary [Hill 2022]

Letter [Martinac 2022]

Commentary [Basu et al. 2022]

Review

[Sasaki 2022]

Review

[Zhang et al. 2022]

Review

[Oyama et al. 2022]

Review

[Hou and Tochio 2022]

Review

[Rajput et al. 2022]

Review

[Kataoka et al. 2022]

Review

[Mohammadi and Bavi 2022]

Review

[Carey et al. 2022]

Review

[MacDermott-Opeskin,et al. 2022]

Review

[Crowley et al. 2022]

Review

[Henderson et al. 2022]

Review

[Senju and Tsai 2022]

Review

[Lin et al. 2022]

Review

[Yokoi and Mitsutake 2022]

Review

[Hermans et al. 2022]

Review

[Board et al. 2022]

Review

[Hibino and Hiroaki 2022]

Review

[El Salamouni et al. 2022]

Review

[Nikfariam et al. 2022]

Review

[Khafaji et al. 2022]

Commentary [Crossman 2022]

Review

[Sibbles et al. 2022]

Review

[Tebay et al. 2022]

Review

[Li et al. 2022]

Review

[Grosser et al. 2022]

Review

[Hickey et al. 2022] 
Fig. 1 Results of the 2022 Michèle Auger Award for Young Scientists' Independent Research. Ordinal ranking of the nominated candidates with the judges' scoring presented in the form of an average plus or minus one standard error. Congratulations to this year's winner - Assoc. Prof. Miho Yanagisawa of the University of Tokyo

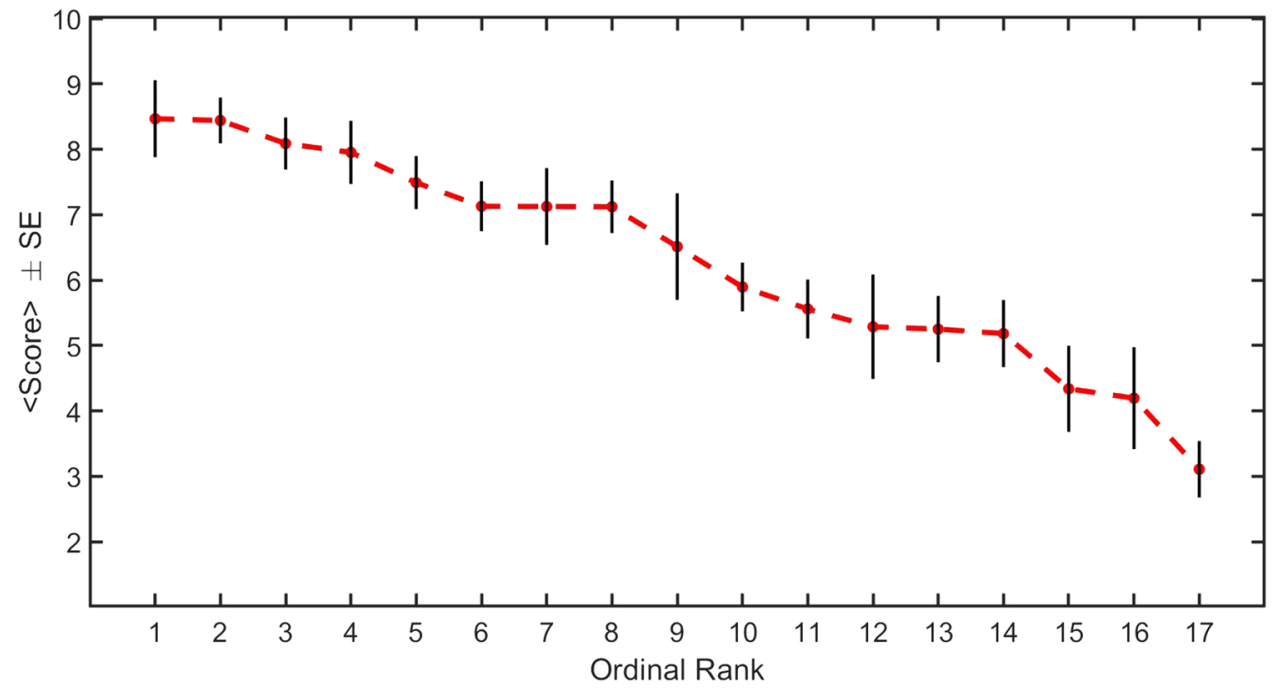

Table 2 The current and prior winners of the Michèle Auger Award for Young Scientists' Independent Research

\begin{tabular}{lll}
\hline Year of award & Name of award recipient & Laboratory website \\
\hline 2022 & Assoc. Prof. Miho Yanagisawa & https://www.c.u-tokyo.ac.jp/info/research/faculty/list/mds/mds-bs/f021974.html \\
& University of Tokyo, Japan & https://sites.google.com/g.ecc.u-tokyo.ac.jp/yanagisawa-lab/ \\
2021 & Assoc. Prof. Jorge Alegre-Cebollada & https://www.cnic.es/en/investigacion/molecular-mechanics-cardiovascular-system \\
& CNIC, Spain & [Alegre-Cebollada 2021] \\
2020 & Assoc. Prof. Alexandra Zidovska & https://as.nyu.edu/content/nyu-as/as/faculty/alexandra-zidovska.html \\
& New York University, USA & [Zidovska 2020] \\
\hline
\end{tabular}

Website: Assoc. Prof. Miho Yanagisawa

https://www.c.u-tokyo.ac.jp/info/research/faculty/list/ mds/mds-bs/f021974.html

https://sites.google.com/g.ecc.u-tokyo.ac.jp/yanagisawa-lab/

As the 2022 recipient, Associate Prof. Yanagisawa will receive a personalized crystal plaque, a complimentary subscription to the journal and a fully paid gold open access payment to cover the costs of publishing a review article based on her research theme, to be published in the 2022 October Issue of Biophysical Reviews (Issue 5). Miho's details along with previous winners of the award in 2021 (Assoc. Prof. Jorge Alegre-Cebollada) and 2020 (Assoc. Prof. Alexandra Zidovska) can be found in Table 2 .

On behalf of the journal, I would like to offer special thanks to the fifteen judges who committed to providing their time over the two-month period of November and December. I would also like to thank those scientists who took the time to nominate a junior colleague. In the often self-absorbed and self-promotional world of research, this ability to step outside of one's own career goals and ambitions, to recognize and promote junior talent, is absolutely essential for maintaining and perpetuating healthy structures in science. Importantly, a special thanks, on behalf of the journal, is also given to all participants of this year's award cycle. Judges were asked to mark across the full scale with some candidates being pipped by others simply due to the strictures of the judging requirements (e.g., independence). While there can only be one winner, participation in the award process is, by design, meant to be a positive experience for all candidates. In this regard, all nominees have had their papers and c.v.'s carefully read by a large number of very senior biophysical scientists, with all nominees rated as good or better by the judging panel. Such exposure, involving the circulation of one's research work among such an eminent circle of readers, is an excellent way of advertising your research progress.

The call for nominations for the 2023 Michèle Auger Award for Young Scientists' Independent Research will be released in the Biophysical Reviews' 2022 June Issue. We ask interested parties to invest some time into thinking who they may like to nominate for the next year's award.

\section{Finalized Special Issue line-up for 2022}

Each year, the journal receives proposals from guest editorial teams for the production of "Special Issues" which consist of a set of related review articles linked by a single-thematic topic. These themed collections can take the form of either a Special Issue (a whole Issue dedicated to a single topic) or an Issue Focus (five or more articles appearing as a contiguous block within a regular Issue). With the release of an announcement-style Commentary in the current Issue describing the final SI for 2022 on the topic of "Computational biophysics 
Table 3 Biophysical Reviews Issue structure for 2022

Issue type and theme

Issue 1: special issue

"The Australian Society for Biophysics"

Issue 2: regular issue with issue focus on "Costa Rican Biophysical Society"

Issue 3: regular issue

Issue 4: special issue

"Congress of the Russian Biophysical Society"

Issue 5: regular issue with issue focus on

"Celebrating the works of Har Gobind Khorana $100^{\text {th }}$ anniversary of his birth"

Issue 6: special issue

"Computational biophysics and structural biology of proteins - Haruki Nakamura $70^{\text {th }}$ birthday"
Special issue guest editors

Charles Cranfield-University of Technology Sydney, Australia

Donna Whelan-La Trobe University, Australia

Charles Cox-Victor Chang Cardiac Research Institute, Australia

Keith Shearwin-The University of Adelaide, Australia

Joshua Ho-University of Hong Kong, Hong Kong

Toby Allen-RMIT University, Australia

Risa Shibuya-AIST, Japan

Emi Hibino—Nagoya University, Japan

Kumiko Hayashi-Tohoku University, Japan

Cristobal dos Remedios-VCCRI, Australia

Amy Li-La Trobe University, Australia

Gustavo Chaves-Institute of Physiology, Pathophysiology and Biophysics, Klinikum Nürnberg Medical School, Germany

José Rodríguez-Corrales-Universidad Nacional de Costa Rica, Costa Rica

Christopher Solis-The University of Illinois at Chicago, USA

N/A

Anatoly Tsygankov—Russian Academy of Sciences, Russia

Andrew Rubin-Lomonosov Moscow State University, Russia

Valery Tuchin—Saratov State University, Russia

Galina Riznichenko-Lomonosov Moscow State

University, Russia

Alexei Solovchenko-Lomonosov Moscow State University, Russia

Gopala Krishna-Indian Institute of Technology Madras, India

N.R. Jagannathan-Chettinad Academy of Research \& Education, India

Gautam Basu-Department of Biophysics, Bose Institute. India

Damien Hall—Nano Life Science Institute Kanazawa

University, Japan

Nobutoshi Ito-Medical Research Institute, Tokyo

Medical and Dental University (TMDU), Japan
Published synopsis/lead contact

[Cranfield et al. 2021]

Contact: Dr. Amy Li

Email: Amy.Li@latrobe.edu.au

[Solis et al. 2021]

Contact: Dr. Gustavo Chaves

Email: Gustavo.Chaves@

klinikum-nuernberg.de

N/A

[Tsygankov et al. 2021]

Contact: Dr. Anatoly Tsygankov

Email: ttt-00@mail.ru

Contact: Dr. Gopala Krishna

Email: agk@iitm.ac.in

[Basu et al. 2022]

Email: gautam@jcbose.ac.in and structural biology of proteins-A Special Issue in Honor of Prof. Haruki Nakamura's $70^{\text {th }}$ birthday" [Basu et al. 2022], this year's Special Issue line-up is now set. The Issue structure for 2022 is provided in Table 3.

Those wishing to use Biophysical Reviews as a vehicle to drive the publication of their own SI or Issue Focus for 2023 are asked to contact either the Chief Editor or one of the seven Executive Editors for further discussions (generally, discussions should begin more than a year in advance). The senior editorial members of the journal can be contacted by email as follows.

Damien Hall (Chief Editor)

Kanazawa University, Japan

hall.damien@staff.kanazawa-u.ac.jp
Wilma Olson (Executive Editor)

Rutgers University, USA

wilma.olson@ rutgers.edu

N. Jaganathan (Executive Editor)

Chettinad Academy of Research \& Education, India

jagan1954@hotmail.com

Kuniaki Nagayama (Executive Editor)

National Institute for Physiology, Japan

nagayama@nips.ac.jp

Stephen Harding (Executive Editor)

University of Nottingham, UK

steve.harding@nottingham.ac.uk

Joshua Ho (Executive Editor) 
University of Hong Kong, China

jwkho@hku.hk

German Rivas (Executive Editor)

CIB, CSIC, Spain

grivas@cib.csic.es

Rosangela Itri (Executive Editor)

University of São Paulo, Brazil

itri@if.usp.br

\section{New services offered to authors}

As of 2022, Biophysical Reviews has joined the SpringerNature/Research Square "In Review" service [IR SpringerNature 2022] which offers authors the ability to both, create a preprint of their submitted work (replete with a DOI), and then share that preprint via the preprint server's in house file transfer protocol system. The "In Review" site can also be used to track the progress of their submitted manuscript through the review process and also promote their newly accepted manuscripts via an email alert and sharing system built into the site. Participation with the system is voluntary and all coauthors must agree prior to a preprint being created on the Research Square server prior to this action being processed. More can be read about the "In Review" service by clicking on the website link associated with the following reference [IR Springer-Nature 2022].

\section{Announcing new editorial board members}

As an organization engaged in the conveyance of information between humans, the Biophysical Reviews journal is only as good as the members it is composed of. In this spirit, Biophysical Reviews would like to thank both the existing members and the following new members (shown in bold in Table 4) of the Editorial Board for kindly donating their time in service of the journal. The very recent addition of nominated editorial board members from India (A. Chattopadathy), England (T. Iskratch), and Australia (F. Braet), along with a number of automatic appointments to the Editorial Board due to their election as IUPAB councilors from Russia (A.A. Anashkina), Argentina (G. Amodeo), Australia (M. Baker), New Zealand (D. Crossman), Germany (H.J. Galla), USA (A.M. Gronenborn), Japan (T. Nishizaka), France (C. Sizun), Italy (C. Viero), and the UK (A. Watts), will undoubtedly help Biophysical Reviews in its ongoing quest to provide service to the international biophysics community.

\section{Concluding remarks}

Those interested in submitting an article to Biophysical Reviews should discuss the matter with either the Chief Editor or a close by Executive or Editorial Board Member. More information about the journal is available at its official Springer-Nature website and social media pages on Twitter and YouTube.

Web: https://www.springer.com/journal/12551

Twitter: @BiophysicalRev1.

YouTube:www.youtube.com/channel/UCzG_5MWmn rB2UBibtxs2DuA

After establishing the appropriateness of your suggested topic, a general timetable for the submission of your article (usually about 4 to 6 months following the official invitation) will be arranged in conjunction with the professional officers of the journal.

Table 4 Biophysical Reviews Editorial Board for 2022

\begin{tabular}{|c|c|}
\hline \multicolumn{2}{|l|}{ Chief editor } \\
\hline Damien Hall & Nano Life Science Institute Kanazawa University, Japan \\
\hline \multicolumn{2}{|l|}{ Emeritus chief editors } \\
\hline Cristobal dos Remedios & Victor Chang Cardiac Research Institute, Darlinghurst, NSW, Australia \\
\hline Jean Garnier & International Science Council, France \\
\hline \multicolumn{2}{|l|}{ Executive editors } \\
\hline S. Harding & Department of Bioscience, University of Nottingham, England \\
\hline J.W. K. Ho & Li Ka Shing Faculty of Medicine, The University of Hong Kong, China \\
\hline R. Itri & Institute of Physics, University of Sao Paolo, Sao Paolo, Brazil \\
\hline N. R. Jagannathan & Chettinad Academy of Research \& Education, India \\
\hline K. Nagayama & National Institute for Physiological Sciences, Okazaki, Japan \\
\hline W. Olson & Department of Chemistry and Chemical Biology, Rutgers University, USA \\
\hline G. Rivas & Centro de Investigaciones Biológicas -CIB, CSIC \\
\hline
\end{tabular}


Table 4 (continued)

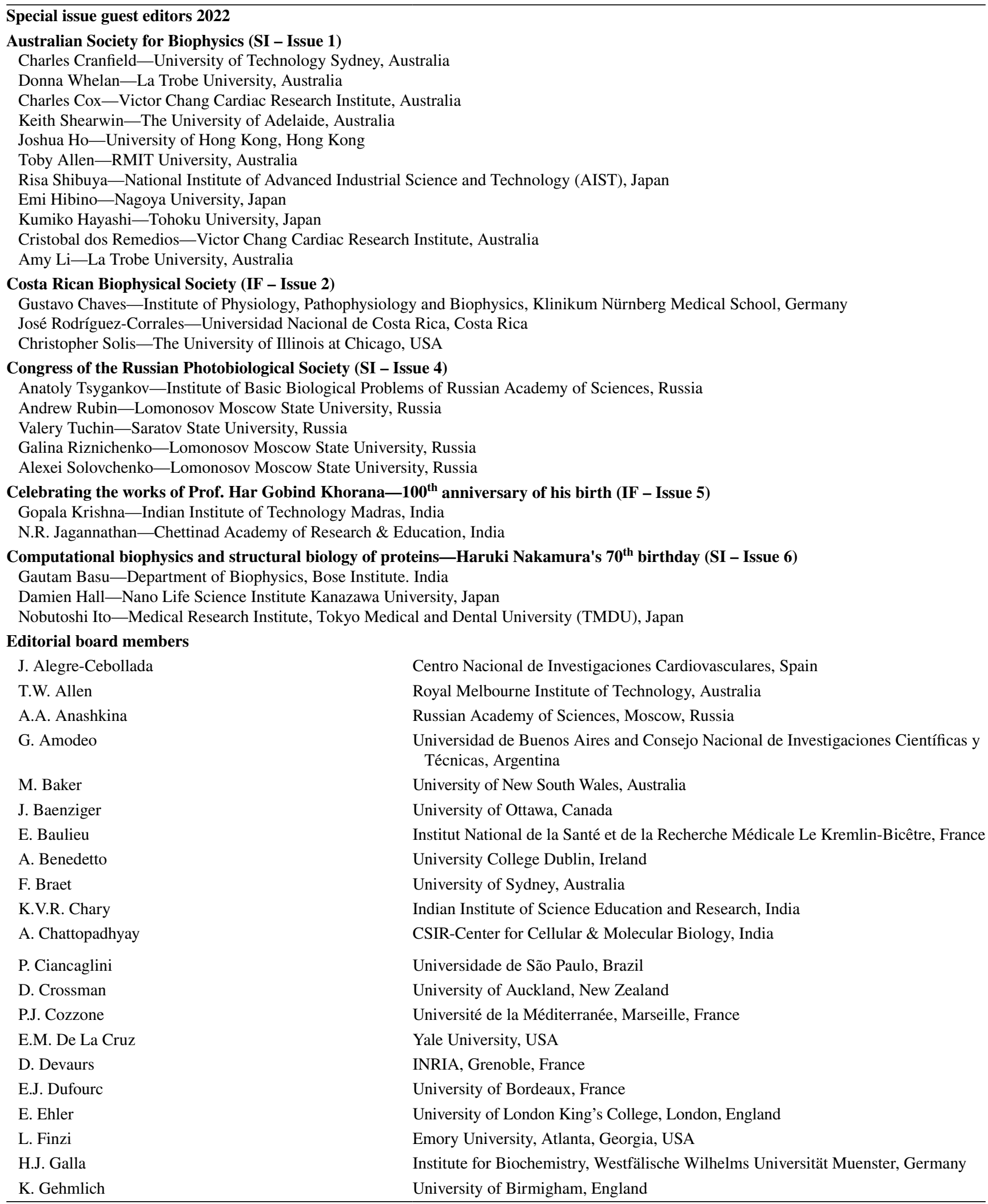


Table 4 (continued)

\begin{tabular}{|c|c|}
\hline J. C. Gómez-Fernández & University of Murcia, Spain \\
\hline A.M. Gronenborn & University of Pittsburgh, USA \\
\hline S.J. Harding & University of Nottingham, England \\
\hline J. Higo & University of Hyogo, Japan \\
\hline T.Iskratch & Queen Mary University of London, UK \\
\hline P. Karthe & CAS in Crystallography and Biophysics, University of Madras, India \\
\hline A.R. Kinjo & Department of Mathematics, Universiti Brunei Darussalam, Brunei \\
\hline J. Kozelka & University Paris Diderot, France \& Masaryk University, Czech Republic \\
\hline T. Kraft & Hannover Medical School, Germany \\
\hline K. K. Kim & Sungkyunkwan University, Republic of Korea \\
\hline A. Li & Latrobe University, Australia \\
\hline S. Leslie & McGill University, Canada \\
\hline B. Maggio & Universidad Nacional de Córdoba, Argentina \\
\hline B. Martinac & Victor Chang Cardiac Research Institute, Australia \\
\hline J.W. McNamara & University of Cincinnati, USA \\
\hline M.M. Morales & Cidade Universitária, Brazil \\
\hline H. Nakamura & Institute of Protein Research, Osaka University, Japan \\
\hline T. Nishizaka & Gakushuin University, Japan \\
\hline H. Noji & The University of Tokyo, Japan \\
\hline R.D. Peluffo & University of the Republic, Uruguay \\
\hline P. Pohl & University Linz, Austria \\
\hline M. Prietto & University of Lisbon, Portugal \\
\hline K. Radotic & University of Belgrade, Serbia \\
\hline C.M. Rao & Center for Cellular and Molecular Biology, India \\
\hline Z. Rao & Tsinghua University, China \\
\hline C. Royer & Rensselaer Polytechnic Institute, USA \\
\hline F. Separovic & University of Melbourne, Australia \\
\hline B. T. Sewell & University of Cape Town, South Africa \\
\hline C. Sizun & Center National de la Recherche Scientifique, France \\
\hline K. Shearwin & Molecular and Biomedical Science, University of Adelaide, Australia \\
\hline A. Shonhai & University of Venga, South Africa \\
\hline C.M. Soares & Universidade Nove de Lisboa, Portugal \\
\hline A.H. Squires & University of Chicago, USA \\
\hline D. Szczesna-Cordary & University of Miami, USA \\
\hline J. Tame & Yokohama City University, Japan \\
\hline S. del Valle Alonso & Universidad Nacional de Quilmes, Argentina \\
\hline J. van der Velden & VU University Medical Center, The Netherlands \\
\hline M. Vassalli & University of Glasgow, Scotland \\
\hline G. Viero & Institute of Biophysics, CNR, Italy \\
\hline A. Watts & University of Oxford, UK \\
\hline M. Williams & Massey University, New Zealand \\
\hline G.J.L. Wuite & VU University Amsterdam, The Netherlands \\
\hline K. Yasuda & Waseda University, Japan \\
\hline B. Zapotoczny & Institute of Nuclear Physics, Polish Academy of Sciences, Poland \\
\hline A. Zidovska & New York University, USA \\
\hline G. Zucchelli & Università degli Studi di Milano, Italy \\
\hline
\end{tabular}


Acknowledgements I would like to especially thank Dr. Meran LloydOwen and Prof. Adam S. Foster for comments made on an earlier draft of this manuscript. DH acknowledges funding associated with the receipt of a "Tokunin" Assistant Professorship carried out at the WPI-Center for Nano Life Science, Kanazawa University. DH also acknowledges the University of Aalto, for an appointment to their Affiliated Researcher Program carried out within the Department of Applied Physics.

\section{Declarations}

Conflict of interest The author declares no competing interests.

\section{References}

Alegre-Cebollada J (2021) Protein nanomechanics in biological context. Biophys Rev 13:435-454. https://doi.org/10.1007/ s12551-021-00822-9

Basu G, Hall D, Ito N (2022) Biophysical reviews special issue call: computational biophysics and structural biology of proteins-a special issue in honor of Prof. Haruki Nakamura's 70th birthday. Biophys Rev 14(1). https://doi.org/10.1007/ s12551-022-00934-w

Board AJ, Crowther JM, Acevedo-Fani A, Meisrimler CN, Jameson GB, Dobson RCJ (2022) How plants solubilise seed fats: revisiting oleosin structure and function to inform commercial applications. Biophys Rev 14(1). https://doi.org/10.1007/ s12551-021-00923-5

Carey AB, Ashenden A, Köper I (2022) Model architectures for bacterial membranes. Biophys Rev 14(1)

Cranfield C, Whelan D, Cox C, Shearwin K, Ho J, Allen T, Shibuya R, Hibino E, Hayashi K, dos Remedios C, Li A (2021) Announcing the call for the Special Issue on "The Australian Society for Biophysics (ASB) - 2021 Meeting”. Biophys Rev 13:485-486. https://doi.org/10.1007/s12551-021-00813-w

Crossman DJ (2022) Fibrosis and impaired Ca2+ signalling in heart failure. Biophys Rev 14(1). https://doi.org/10.1007/ s12551-021-00909-3

Crowley J, Withana M, Deplazes E (2022) The interaction of steroids with phospholipid bilayers and membrane. Biophys Rev 14(1). https://doi.org/10.1007/s12551-021-00918-2

dos Remedios C, Cranfield C, Whelan D, Cox C, Shearwin K, Ho JWK, Allen T, Shibuya R, Hibino E, Hayashi K, Li A (2022) A special issue of the Australian Society for Biophysics. Biophys Rev 14(1)

El Salamouni NS, Buckley BJ, Ranson M, Kelso MJ, Yu H (2022) Urokinase plasminogen activator as an anti-metastasis target: inhibitor design principles, recent amiloride derivatives, and issues with human/mouse species selectivity. Biophys Rev 14(1). https://doi.org/10.1007/s12551-021-00921-7

Grosser M, Lin H, Wu M, Zhang Y, Tipper S, Venter D, Lu J, dos Remedios CG (2022) A bibliometric review of peripartum cardiomyopathy compared to other cardiomyopathies using artificial intelligence and machine learning. Biophys Rev 14(1). https://doi. org/10.1007/s12551-022-00933-x

Hall D (2020a) Biophysical Reviews' national biophysical society partnership program. Biophys Rev 12(2):187-192. https://doi.org/10. 1007/s12551-020-00693-6

Hall D (2020b) A new decade for Biophysical Reviews and a look into the future of biophysics. Biophys Rev 12(1):1-7. https://doi.org/ 10.1007/s12551-020-00622-7
Hall D (2020c) Biophysical Reviews-quantitative analysis of biological phenomenon. Biophys Rev 12(3):601-605. https://doi.org/10. 1007/s12551-020-00702-8

Hall D (2021a) Biophysical Reviews - the IUPAB journal tasked with advancing biophysics. Biophys Rev 13:1-6. https://doi.org/10. 1007/s12551-021-00788-8

Hall D (2021b) Biophysical reviews - a call to young biophysicists. Biophys Rev 13(3):289-294. https://doi.org/10.1007/ s12551-021-00810-z

Hall D (2022) Biophysical Reviews: from the umbra of 2020-2021 into the antumbra of 2022. Biophys Rev 14(1):1-10

Harada Y (2020) Greetings from the President of the Biophysical Society of Japan. Biophys Rev 12(2):201-203. https://doi.org/10.1007/ s12551-020-00677-6

Henderson SW, Nourmohammadi S, Ramesh SA, Yool AJ (2022) Aquaporin ion conductance properties defined by membrane environment, protein structure, and cell physiology. Biophys Rev 14(1). https://doi.org/10.1007/s12551-021-00925-3

Hermans SJ, Nero TL, Morton CJ, Gooi JH, Crespi GAN, Hancock NC, Gao C, Ishii K, Markulić J, Parker MW (2022) Structural biology of cell surface receptors implicated in Alzheimer's disease. Biophys Rev 14(1). https://doi.org/10.1007/s12551-021-00903-9

Hibino E, Hiroaki H (2022) Potential of rescue and reactivation of tumor suppressor p53 for cancer therapy. Biophys Rev 14(1). https://doi.org/10.1007/s12551-021-00915-5

Hickey T, Devaux J, Rajagopal V, Power A, Crossman D (2022) Paradoxes od Hymenoptera flight muscles, extreme machines. Biophys Rev 14(1) (Current Issue)

Hill AP (2022) Biophysics in the time of COVID. Biophys Rev 14(1). https://doi.org/10.1007/s12551-022-00932-y

Hou XN, Tochio H (2022) Characterizing conformational ensembles of multi-domain proteins using anisotropic paramagnetic NMR restraints. Biophys Rev 14(1). https://doi.org/10.1007/ s12551-021-00916-4

IR Springer-Nature (2022) https://www.springernature.com/gp/autho rs/campaigns/in-review (webpage Accessed 7/2/2022)

ISC (2022) https://council.science/ (International Science Council webpage Accessed 7/2/2022)

IUPAB (2019) Newsletter, issue 70 (February). http://iupab.org/2018/ 11/06/obituary-michele-auger-former-iupab-councilor/ (webpage Accessed 7/2/2022)

IUPAB (2022) http://iupab.org/ (International Union for Pure and Applied Biophysics webpage Accessed 7/2/2022)

Kataoka K, Togawa Y, Sanno R, Asahi T, Yura K (2022) Dissecting cricket genomes for the advancement of entomology and entomophagy. Biophys Rev 14(1). https://doi.org/10.1007/ s12551-021-00924-4

Khafaji M, Bavi O, Zamani M (2022) Gold-based hybrid nanostructures: more than just a pretty face for combinational cancer therapy. Biophys Rev 14(1). https://doi.org/10.1007/ s12551-021-00926-2

Komatsuzaki T, Nakamura H, Tame J, Yanaka S, Nagai T, Nagayama K (2020) Editorial for the Special Issue of Biophysical Reviews focused on the Biophysical Society of Japan with select scientific content from the 57th BSJ annual meeting, Miyazaki, Japan. Biophys Rev 12(2):183-185

Li A, Campbell K, Lal S, Ge Y, Keogh A, Macdonald PS, Lau P, Lai J, Linke WA, Van der Velden J, Field A, Martinac B, Grosser M, dos Remedios C (2022) Peripartum cardiomyopathy: a global effort to find the cause and cure for the rare and little understood disease. Biophys Rev 14(1). https://doi.org/10.1007/s12551-022-00930-0

Lin Y, Buyan A, Corry B (2022) Computational studies of Piezo1 yield insights into key lipid-protein interactions, channel activation, and agonist binding. Biophys Rev 14(1). https://doi.org/10.1007/ s12551-021-00847-0 
MacDermott-Opeskin HO, Gupta V, O’Mara M.L. (2022) Lipid-mediated antimicrobial resistance: a phantom menace or a new hope? Biophys Rev 14(1) (Current Issue)

Martinac B (2022) 2021 Nobel prize for mechanosensory transduction. Biophys Rev 14(1) (Current Issue)

Mohammadi MM, Bavi O (2022) DNA sequencing: an overview of solid-state and biological nanopore-based methods. Biophys Rev 14(1). https://doi.org/10.1007/s12551-021-00857-y

Morales MM (2021) IUPAB - serving the international biophysics community. Biophys Rev 13(3):303-305

Nikfarjam Z, Zargari F, Nowroozi A, Bavi O (2022) Metamorphosis of prostate specific membrane antigen (PSMA) inhibitors. Biophys Rev 14(1). https://doi.org/10.1007/s12551-021-00919-1

Oyama K, Ishii S, Suzuki M (2022) Opto-thermal technologies for microscopic analysis of cellular temperature-sensing systems. Biophys Rev 14(1):1-14. https://doi.org/10.1007/ s12551-021-00854-1

Rajput S, Yao S, Keizer DW, Sani MA, Separovic F (2022) NMR spectroscopy of lipidic cubic phases. Biophys Rev 14(1). https://doi. org/10.1007/s12551-021-00900-y

Sasaki A (2022) Recent advances in the standardization of fluorescence microscopy for quantitative image analysis. Biophys Rev 14(1). https://doi.org/10.1007/s12551-021-00871-0

Senju Y, Tsai FC (2022) A biophysical perspective of the regulatory mechanisms of ezrin/radixin/moesin proteins. Biophys Rev 14(1). https://doi.org/10.1007/s12551-021-00928-0

Sibbles ET, Waddell HMM, Mereacre V, Jones PP, Munro ML (2022) The function and regulation of calsequestrin-2: implications in calcium-mediated arrhythmias. Biophysical Reviews 14(1). https://doi.org/10.1007/s12551-021-00914-6

Solís C, Chaves G, Rodriguez-Corrales JÁ (2021) Announcing the call for the Issue Focus on the 2nd Costa Rican Biophysics Symposium—virtual meeting. Biophys Rev 13:487-488. https://doi.org/ 10.1007/s12551-021-00816-7

TeBay C, Hill A, Windley M (2022) Metabolic and electrolyte abnormalities as risk factors in drug-induced long QT syndrome. Biophys Rev 14(1). https://doi.org/10.1007/s12551-022-00929-7

Tsygankov A, Rubin A, Tuchin V, Riznichenko G, and Solovchenko A (2021) Call for contributions to the Special Issue on the 9th Congress of the Russian Photobiological Society held in Shepsi, Krasnodar region, Russia. Biophys Rev 13:815-816. https://doi. org/10.1007/s12551-021-00905-7

Yokoi S, Mitsutake A (2022) Characteristic structural difference between inactive and active states of orexin 2 receptor determined using molecular dynamics simulations. Biophys Rev 14(1):1-11. https://doi.org/10.1007/s12551-021-00862-1

Zhang MJ, Stear JH, Jacques DA, Böcking T (2022) Insights into HIV uncoating from single-particle imaging techniques. Biophys Rev 14(1):1-10. https://doi.org/10.1007/s12551-021-00922-6

Zidovska A (2020) The rich inner life of the cell nucleus: dynamic organization, active flows, and emergent rheology. Biophys Rev 12:1093-1106. https://doi.org/10.1007/s12551-020-00761-x

Publisher's note Springer Nature remains neutral with regard to jurisdictional claims in published maps and institutional affiliations. 